\title{
Articles
}

The Person and the Challenges

Volume 2 (2012) Number 1, p. 15-20

Gerhard Ludwig Müller

Ludwig Maximilians University

Munich, Germany

\section{Johannes Paul II. lebt weiter in seinen Enzykliken}

\author{
John Paul II is still Alive in His Encyclicals
}

\begin{abstract}
Blessed John Paul II has very clearly recognised the signs of time. He has also observed the destructive impulses in the West societies during the past several decades and has consistently pointed out in his encyclicals that in its search for identity and meaning, modern humanity was not able to find a purpose and reason for living. His encyclics are precious gifts and directions for the Third Millenium. The most important aspects of his teaching are: Christ in the centere, co-workers of Kingdom of God, anthropology, reason and faith, defending life, Ut unum sint - the commitment to ecumenism, Totus tuus - the life of faith.
\end{abstract}

\section{Keywords}

John Paul II, encyclicals.

Am 1. Mai 2011 hat unser Heiliger Vater, Papst Benedikt XVI., den verehrten Johannes Paul II. selig gesprochen. Er hat die Kirche in das dritte Jahrtausend geführt und die Zeichen der Zeit am Ende des 20. Jahrhunderts zu deuten verstanden. All sein Tun und Handeln, seine Gesten und Worte fanden ihren Niederschlag in seinen lehramtlichen Texten und speziell in den Enzykliken, 
die er der Kirche geschenkt hat. Zur Erinnerung an den großen Seligen sei noch einmal an die Schwerpunkte seiner Enzykliken erinnert.

\section{Christus ist die Mitte}

Johannes Paul II. hat sich wie kein Anderer so mit Christus verbunden gewusst. Sein Wirken als Pontifex ist mit der ersten Enzyklika „Redemptor hominis“ bereits geprägt gewesen von einer inneren und unverbrüchlichen Verbindung mit Jesus Christus. Ausgerichtet auf den Herrn und Erlöser wurde seine irdische Pilgerreise zu einem Hoffnung gebenden Zeichen der Universalität der Offenbarung Gottes in Jesus Christus. „Und in keinem anderen ist das Heil zu finden. Denn es ist uns Menschen kein anderer Name gegeben unter dem Himmel, durch den wir selig werden" ${ }^{\text {"1. }}$ Es sind zwei Dimensionen seines päpstlichen Wirkens, die uns immer wieder so fasziniert haben: Sein Wirken in der Welt und sein Schauen auf Christus.

\section{Mitarbeiter am Reiche Gottes}

Sein unermüdlicher Einsatz für ein Leben in der Vernunft Gottes, das sich stets stärker erwiesen hat als die politisch-ideologischen Heilslehren, die nur von Menschen ersonnen sind, war faszinierend. Die Vernunft Gottes, das WORT, das unser Fleisch angenommen hat ${ }^{2}$, die vertrauensvolle Hingabe an den Schöpfer und Vollender des Menschen, hat uns immer wieder die Machtlosigkeit menschlicher Organisationen vor Augen geführt, die den Wesensbezug des Menschen zu Gott verschwiegen oder bekämpft haben. Unvergessen werden die Bilder sein, die Johannes Paul II. mit den politischen Machthabern der Welt zeigen und denen er gerade in den bedrohlichen Zeiten bevorstehender Kriege das Gebot der Versöhnung und der Liebe predigte. Seine Botschaft war nicht politisch-innerweltlicher Natur. Sie ist erwachsen aus der Verantwortung gegenüber dem Zeugnis der Wahrheit, die Jesus Christus selbst ist. Vor Pilatus, dem irdischen Machthaber, offenbart Jesus das Geheimnis seiner Person und Sendung: „Ja, ich bin ein König. Dazu bin ich geboren und in die Welt gekommen, um für die Wahrheit Zeugnis abzulegen. Jeder, der aus der Wahrheit ist, hört auf meine Stimme“33.

\footnotetext{
${ }^{1}$ Apg 4,12.

${ }^{2}$ Vgl. Joh 1,14 .

${ }^{3}$ Joh 18,37 .
} 


\section{Der Mensch als Maßstab - Die Soziale Frage}

Damit sind auch die Themen angesprochen, die den Alltag der Menschen beschreiben. Die tägliche Arbeit, mit der sich Johannes Paul II. in der Enzyklika „Laborem exercens" ${ }^{64}$ und in „Sollicitudo rei socialis“ ${ }^{“ 5}$ beschäftigte. So ist die Arbeit nicht nur ein Produktionsfaktor, der sich in den Dienst der Wirtschaftlichkeit und der Effizienz zu stellen hat, sondern ein Bestandteil wahren Menschseins. Auch hier spiegelt sich die enge Verknüpfung von Christus und den Menschen, der Christologie und der Anthropologie, in der Botschaft des Papstes wieder.

Sein ,politisches Handeln“ ist jedoch nicht einfügbar in die Politik, die zur Durchsetzung ihrer Interessen auf Mittel zurückgreift, die in den zeitbedingten gesellschaftlichen Formen auch stets nur zeitlich begrenzte Entscheidungen treffen kann. Die in den Enzykliken geäußerte Lehre der Kirche ist eine bleibende, Veränderung überdauernde Kraft, deren Autorität und Verbindlichkeit in Jesus Christus begründet liegt.

Das zeigt sich im überzeitlichen Engagement der Kirche für die Not der Armen, der Unterdrückten und Behinderten, die keinen Anwalt in der Menschheitsfamilie haben - außer der Kirche.

\section{Vernunft und Glaube}

Neben den großen Texten zur wirtschaftlichen und politischen Realität finden wir auch die großen Antworten zum Verhältnis der Vernunft zum Glauben. Seit der Aufklärung wird die Unvereinbarkeit von Vernunft und Offenbarung konstruiert. Der Glaube ist in das persönlich-subjektive Empfinden verdrängt worden und seiner Öffentlichkeit und Vernünftigkeit beraubt. Ist seitdem die Welt besser und vernünftiger geworden? Johannes Paul II. hat in seiner Enzyklika „Fides et ratio"6 den Zusammenhang von Vernunft und Glaube mit folgenden Worten umschrieben: „Glaube und Vernunft sind wie die beiden Flügel, mit denen sich der menschliche Geist zur Betrachtung der Wahrheit erhebt. Das Streben, die Wahrheit zu erkennen und letztlich ihn selbst zu erkennen, hat Gott dem Menschen ins Herz gesenkt, damit er dadurch, dass er Ihn erkennt und liebt, auch zur vollen Wahrheit über sich selbst gelangen könne“ (Einleitung). Vernunft und Glaube sind keine gegensätzlichen Pole der menschlichen Wirklichkeit, sondern

\footnotetext{
${ }^{4}$ Johannes Paul II., Enzyklika Laborem exercens (1981).

${ }^{5}$ Johannes Paul II., Enzyklika Sollicitudo rei socialis (1987).

${ }^{6}$ Johannes Paul II., Enzyklika Fides et ratio (1998).
} 
aufeinander zugeordnete Wege zu Gott und zum eigenen Menschsein. Allein die Frage „Wer bin ich“ setzt ein rationales Denken in Gang, das aber seinen eigentlichen Ursprung in der Erkenntnis der Abhängigkeit von Gott besitzt. Unser Glaube strebt eben nach der geistigen Durchdringung und die rationale Erkenntnis führt uns immer mehr in das Geheimnis unseres Glaubens. Die Offenbarung kann nicht vor das Tribunal der begrenzten menschlichen Vernunft gezogen werden. Sie bietet der Vernunft erst den Raum zu sich selbst und damit zum Ziel der Wahrheit zu finden, die allein Gott ist. Alle Wahrheit der menschlichen Vernunft hat in Gott ihren Ausgangspunkt, Stütze, Inhalt und Ziel.

\section{Schützt das Leben!}

Wer erinnert sich in diesen Tagen der Seligsprechung nicht auch besonders an den unermüdlichen Einsatz Johannes Pauls II. für das Leben - von seinem Beginn im ersten Augenblick der Empfängnis bis zum letzten Atemzug des natürlichen Todes. In „Evangelium vitae ${ }^{\text {“7 }}$ setzte er noch einmal Maßstäbe für den Umgang mit dem Leben. Unantastbarkeit, Freiheit, Würde und Respekt sind dem Leben aus sich selbst heraus zu Eigen. Niemals darf sich der Mensch zum Herrn des Lebens aufspielen, denn die daraus resultierende Gefahr liegt in der Manipulierbarkeit und in der grausamen Geringschätzung des Rechts auf Leben.

\section{Ut unum sint - Das ökumenische Engagement}

Die Ökumene ist Johannes Paul II. immer besonders am Herzen gelegen. Zuletzt in der Enzyklika „Ut unum sint"“8. Sein Appell, sich dem Aufruf Jesu Christi zu stellen und für die Einheit der Kirche zu arbeiten, ist unüberhörbar. Ökumene wird am meisten befördert, wo sie sich dem Anspruch der Wahrheit stellt. Der Relativismus ist der größte Feind der Ökumene und nichts anders als menschliche Besserwisserei gegenüber dem Mensch gewordenen Wort, dem einzigen Sohn des Vaters - „voll der Gnade und Wahrheit“9. Die Einheit der Kirche Christi, die schon verwirklicht ist in der Einheit der katholischen Kirche in Gemeinschaft mit den Bischöfen und mit dem Papst als Prinzip und Fundament ihrer Einheit, ist offen für die volle Gemeinschaft aller Christen in ihr. Die katholische Kirche

\footnotetext{
${ }^{7}$ Johannes Paul II., Enzyklika Evangelium vitae (1995).

${ }^{8}$ Johannes Paul II., Enzyklika Ut unum sint (1995).

${ }^{9}$ Joh 1,14 .
} 
bewahrt ihre Identität und anerkennt zugleich die Elemente der Wahrheit und Heiligung außerhalb ihrer, die als der Kirche Christi eigene Gaben zur vollen sichtbaren Einheit mit der katholischen Kirche hindrängen ${ }^{10}$.

\section{Totus tuus - Ein Leben aus dem Glauben}

Seinen Wahlspruch hat er in überzeugender Weise auch vorgelebt und wurde dadurch für uns alle zum Vorbild in unserer Lebensgestaltung. Christsein ist eine Entscheidung, die unser Leben in all seinen Facetten und Formen umgreift. Bereits seine erste Enzyklika „Redemptor hominis“11 hat den Weg vorgezeichnet, den sein Wirken beschreiten wird. Jesus Christus ist der Erlöser des Menschen. Und die Erkenntnis des Bezogenseins auf Jesus Christus ist auch der Zugang zur Erkenntnis wahren Menschseins, das sich in der Hinordnung auf Gott seiner eigenen Dimension bewusst wird. Schauen wir voller Dankbarkeit zurück auf die fast 27 Jahre von Papst Johannes Paul II., so finden wir diese Ausrichtung auf Jesus Christus selbst in seiner letzten Enzyklika „Ecclesia de Eucharistia“ ${ }^{\text {"12 }}$ noch einmal bestätigt. Im letzten Abendmahl hat Christus selbst uns seinen Leib und sein Blut geschenkt und uns im Sakrament der Eucharistie zur Kirche gestaltet. Christus und die Kirche gehören zusammen.

Johannes Paul II. ist selbst im Tod zum Zeugen für die Botschaft des Lebens geworden. Seine Zuversicht, seine unauslöschliche Hoffnung auf ein Leben in der Anschauung Gottes, ist keine Vision, keine Erfindung von uns Menschen, sondern die Wirklichkeit des Glaubens. Der Herr des Lebens wird ihm alles vergelten, was er für die Kirche, - für uns getan hat. Der Apostel Petrus, dessen Nachfolger als Bischöfe von Rom die Päpste sind, stellte sich den Bischöfen und Priester vor als Mitpriester und Zeuge der Leiden Christi, der ,auch an der Herrlichkeit teilhaben soll, die sich offenbaren wird“"13.

Als Jesus nach seiner Auferstehung von den Toten dem Apostel Petrus das universale Hirtenamt über seine Kirche übertrug, tat er dies mit den Worten: „Amen! Amen! das sage ich dir: Als du jung warst, hast du dich selbst gegürtet und konntest gehen wohin du wolltest. Wenn du aber alt geworden bist, wirst du deine Hände ausstrecken und ein anderer wird dich führen, wohin du nicht willst.

\footnotetext{
${ }^{10} \mathrm{Vgl}$. Lumen gentium 8.

${ }^{11}$ Johannes Paul II., Enzyklika Redemptor hominis (1979).

${ }^{12}$ Johannes Paul II., Enzyklika Ecclesia de Eucharistia (2003).

${ }^{13} 1$ Petr 5,1.
} 
Das sagte Jesus, um anzudeuten, durch welchen Tod er Gott verherrlichen würde. Nach diesen Wort sagte er: Folge mir nach!“"14.

Johannes Paul II., dem die Schlüssel des Himmelreiches und die Binde- und Lösegewalt von Jesus selbst übertragen worden sind, war im Leben und Sterben, in Gesundheit und Krankheit, in jugendlicher Frische und der Gebrechlichkeit im Alter immer ein Zeuge des leidenden und verherrlichten Christus. Er war der Fels, auf den unüberwindlich von den Mächten des Todes die Kirche Jesu gebaut ${ }^{15}$ ist und zugleich ein heiligmäßiger Christ in der Nachfolge Jesu.

Sein Leben und Wirken als Papst war allein dem Auftrag Jesu verpflichtet: „Du aber stärke deine Brüder" ${ }^{\text {"1616. }}$.

Als neuer Seliger wird er zum Fürsprecher für die Kirche Gottes auf Erden und zum Vorbild im Glauben für jeden einzelnen Menschen.

\section{Bibliography}

Johannes Paul II., Enzyklika Redemptor hominis (1979).

Johannes Paul II., Enzyklika Laborem exercens (1981).

Johannes Paul II., Enzyklika Sollicitudo rei socialis (1987).

Johannes Paul II., Enzyklika Evangelium vitae (1995).

Johannes Paul II., Enzyklika Ut unum sint (1995).

Johannes Paul II., Enzyklika Fides et ratio (1998).

Johannes Paul II., Enzyklika Ecclesia de Eucharistia (2003).

\footnotetext{
${ }^{14}$ Joh 21,18f.

${ }^{15} \mathrm{Vgl}$. Mt 16,18.

${ }^{16} \mathrm{Lk} 22,32$.
} 